\title{
PENGARUH KEPERCAYAAN, PERSEPSI KEMUDAHAN \\ PENGGUNAAN, DAN PERSEPSI KENYAMANAN TERHADAP \\ INTENSI PEMBELIAN ULANG MELALUI E-COMMERCE (STUDI PADA KONSUMEN LAZADA INDONESIA)
}

\author{
Nikita Astria \\ Dr. Rahma Wahdiniwaty, Dra,. M. Si \\ Fakultas Pascasarjana Universitas Komputer Indonesia (UNIKOM)
}

\begin{abstract}
Penggunaan internet untuk aktifitas transaksi bisnis dikenal dengan Electronic Commerce (e-commerce). Hingga saat ini banyak sekali e-commerce didunia, termasuk Indonesia yang bersaing untuk menjadi yang terbaik bagi konsumen. Lazada Indonesia, hanya mampu berada di posisi ke empat jika dibandingkan dengan e-commerce lain. Faktor terpenting yang dapat mendorong konsumen dalam bertransaksi ialah kepercayaan. Selain kepercayaan, penggunaan yang mudah dan dapat memberikan kenyamanan tentu diharapkan oleh konsumen agar dapat menimbulkan intensi pembelian ulang.Oleh karena itu, peneliti melakukan analisis mengenai perilaku konsumen saat berbelanja melalui $e$ commerce.

Penelitian ini bertujuan untuk mengetahui tanggapan konsumen terkait kepercayaan, kemudahan penggunaan, persepsi kenyamanan, ulang serta bagaimana pengaruhnya terhadap intensi pembelian ulang di Lazada Indonesia.

Penelitian ini bersifat kausal komparatif, dengan pendekatan kuantitatif. Penelitian dilakukan dengan analisis statistik menggunakan LISREL. Kuisoner disebar secara online terhadap konsumen Lazada Indonesia dengan jumlah sampel penelitian sebanyak 400 sampel. Hasil menunjukkan bahwa kepercayaan, dan persepsi kenyamanan konsumen terhadap Lazada Indonesia memiliki kategori cukup baik, persepsi kemudahan penggunaan memiliki kategori baik, sementara intensi pembelian ulang konsumen memiliki kategori buruk. Selain itu, untuk analisis verifikatif ditemukan bahwa kepercayaan, kemudahan penggunaan, dan persepsi kenyamanan berpengaruh signifikan terhadap intensi pembelian ulang baik secara simultan maupun parsial.
\end{abstract}

Kata kunci : e-commerce, kepercayaan, persepsi kemudahan penggunaan, persepsi kenyamanan, intensi pembelian ulang 
Internet merupakan sarana elektronik yang dapat dipergunakan untuk berbagai aktivitas seperti komunikasi, riset, transaksi bisnis dan lainnya. Sejak diperkenalkan pada tahun 1969 di Amerika Serikat, internet mengalami perkembangan yang luar biasa. Apalagi dengan diperkenalkannya teknologi World Wide Web (WWW), semakin menambah sempurnanya teknologi tersebut. Teknologi internet menghubungkan ribuan jaringan komputer individual dan organisasi di seluruh dunia. Setidaknya ada enam alasan mengapa teknologi internet begitu populer. Keenam alasan tersebut adalah internet memiliki konektivitas dan jangkauan yang luas; dapat mengurangi biaya komunikasi; biaya transaksi yang lebih rendah; dapat mengurangi biaya agency; interaktif, fleksibel, dan mudah; serta memiliki kemampuan untuk mendistribusikan pengetahuan secara cepat (Wong, 2017:156).

Membuka transaksi bisnis melalui internet bukan berarti terhindar dari kejahatan oleh pihak lain sebagaimana bertransaksi secara konvensional. Potensi kejahatan berupa penipuan, pembajakan kartu kredit (carding), pentransferan dana illegal dari rekening tertentu, dan sejenisnya sangatlah besar apabila sistem keamanan (security) infrastruktur e-commerce masih lemah. Oleh karena itu, keamanan infrastruktur e-commerce menjadi kajian penting dan serius bagi ahli komputer dan informatika (Rofiq, 2007:23)
Dilansir dari CNN Indonesia, bahwa cyber crime (kejahatan di dunia maya) di Indonesia merupakan yang tertinggi kedua di dunia setelah Jepang dengan total serangan sebanyak 90 juta kali selama Januari hingga akhir juni 2016 (cnnindonesia.com, 2018). Sementara itu berdasarkan data, Yayasan Lembaga Konsumen Indonesia (YLKI) telah menerima 642 pengaduan umum sejak JanuariNovember 2017 dengan 101 keluhan belanja online atau sebesar 16\%. Jumlah ini meningkat dua kali lipat dibandingkan tahun 2016 sebesar $8 \%$. Konsumen kerap mengeluhkan lambatnya respon complain $44 \%$, belum menerima barang $36 \%$, sistem merugikan $20 \%$, tidak diberikannya refund $17 \%$, adanya dugaan penipuan $11 \%$, barang yang dibeli tidak sesuai $9 \%$, dugaan kejahatan cyber $6 \%$, pelayanan $2 \%$, harga $1 \%$, informasi $1 \%$, terlambatnya penerimaan barang $1 \%$ saat memesan barang melalui $e$ commerce (Rizki dkk, 2019:51)

Oktarini (2018:2048), dalam mengunjungi sebuah situs ada banyak hal yang dapat menciptakan minat konsumen, salah satunya ialah dengan menciptakan daya tarik situs. Kesenangan saat melihat produkproduk yang ditawarkan pada situs, kebebasan membuka situs belanja online serta pilihan produk yang beragam dapat meningkatkan niat konsumen dalam melakukan pembelian kembali.

Untuk memenuhi kebutuhan dan keinginan konsumen dalam berbelanja secara online, Lazada Indonesia hadir sebagai opsi $e$ commerce yang muncul sejak tahun 
2012. Dengan banyaknya $e$ commerce yang bermunculan hingga saat ini tentunya tidak terlepas dari persaingan yang dihadapi oleh pemilik/pengelola e-commerce tersebut agar tetap eksis dan digunakan masyarakat.

Puspitasari $\quad$ (2017:171) selain kepercayaan, kemudahan penggunaan merupakan hal penting dalam membeli secara online terutama untuk membangun intensi pembelian ulang. Kemudahan penggunaan yang dirasakan konsumen akan mendorong daya belinya di masa akan datang. Kemudahan penggunaan ini berkaitan dengan pengoperasian Lazada, bagi sebagian orang yang baru pertama kali menggunakan suatu system tentunya mengharapkan dapat dengan mudah menggunakannya.

Menurut Baskara (2016:7218) saat menggunakan e-commerce, selain kepercayaan dan kemudahan penggunaan konsumen juga ingin merasa nyaman saat menggunakan $e$ commerce untuk berbelanja. Kenyamanan yang dirasakan saat berbelanja secara daring akan membantu konsumen dalam mendapatkan pengalamanan berbelanja yang menyenangkan. Asyifa (2016:52)Kenyamanan telah diidentifikasi sebagai penentu penting mengapa konsumen memutuskan untuk membeli. Kenyamanan sangat memperkirakan niat untuk kembali ke situs web dan mengukur dimensi dalam hal pengalaman yang asyik, menyenangkan, menarik dan nyaman. Jika konsumen merasa senang dan tumbuh rangsangan selama pengalaman belanja mereka, mereka sangat mungkin untuk terlibat dalam perilaku belanja berikutnya, mereka menelusuri lebih lanjut, terlibat dalam pembelian tidak terencana, dan mencari lebih banyak produk dan kategori.

\section{METHOD}

Penelitian ini merupakan penelitian survei, yaitu penelitian yang mengambil sampel secara langsung dari populasi. Dilihat dari permasalahan yang diteliti, penelitian ini bersifat kausal komparatif (causal comparative research) yang merupakan tipe penelitian dengan karakteristik masalah hubungan sebab akibat antara dua variabel atau lebih. Penelitian kausal komparatif ini juga termasuk penelitian yang mengidentifikasikan fakta yang terjadi sebagai variabel yang dipengaruhi dan melakukan penyidikan terhadap variabelvariabel yang mempengaruhi. Pendekatan penelitian menggunakan pendekatan kuantitatif.

Pengumpulan data di lapangan dilakukan dengan survei menggunakan kuesioner. Kuesioner dikirimkan ke beberapa mailing-list (kelompok diskusi di Internet). Dengan banyaknya pengguna Lazada Indonesia yang setiap harinya selalu bertambah ataupun berhenti menggunakan Lazada, maka jumlah populasi yang diambil dalam penelitian ini merupakan jumlah pengunjung web sebanyak 27.995.900 yang merupakan data pengguna hingga 2019 yang diperoleh saat penelitian dilakukan. Berdasarkan perhitungan Slovin diatas maka disepakati untuk 
menggunakan 400 sampel dalam penelitian ini.

Hipotesis yang diajukan dalam penelitian ini ialah sebagai berikut :

H1: a. Kepercayaan konsumen pada Lazada Indonesia rendah.

b.Persepsi konsumen dalam penggunaan transaksi e-commerce di Lazada Indonesia tidak mudah.

c. Persepsi konsumen dalam transaksi e-commerce pada Lazada Indonesia tidak nyaman.

d. Intensi pembelian ulang konsumen Lazada Indonesia rendah.

$\mathrm{H} 2$ : Terdapat pengaruh kepercayaan terhadap intensi pembelian ulang pada Lazada Indonesia.

H3 : Terdapat pengaruh persepsi kemudahan penggunaan terhadap intensi pembelian ulang pada Lazada Indonesia.

H4 : Terdapat pengaruh persepsi kenyamanan terhadap intensi pembelian ulang pada Lazada Indonesia.

H5 : Terdapat pengaruh kepercayaan, persepsi kemudahan penggunaan, dan persepsi kenyamanan terhadap intensi pembelian ulang pada Lazada Indonesia.

\section{RESULTS AND DISCUSSION}

\section{I. Descriptive Analysis}

Analisis deskriptif dapat digambarkan sebagaimana berikut ini,

\section{Rekapitulasi Hasil Penilaian Konsumen} pada Variabel Kepercayaan ( $\xi 1)$

\begin{tabular}{|c|c|c|c|c|c|}
\hline \multirow[b]{2}{*}{$\begin{array}{l}\mathbf{N} \\
\mathbf{0}\end{array}$} & \multirow[b]{2}{*}{ Indikator } & \multicolumn{2}{|c|}{ Total Skor } & \multirow[b]{2}{*}{$\%$} & \multirow[b]{2}{*}{$\begin{array}{c}\text { Katego } \\
\text { ri }\end{array}$} \\
\hline & & $\begin{array}{c}\text { Aktu } \\
\text { al }\end{array}$ & $\begin{array}{c}\text { Idea } \\
\text { I }\end{array}$ & & \\
\hline 1 & $\begin{array}{l}\text { Kemampu } \\
\text { an }\end{array}$ & 4032 & 8000 & 50,4 & $\begin{array}{l}\text { Tidak } \\
\text { Baik }\end{array}$ \\
\hline
\end{tabular}

\begin{tabular}{clcccc}
2 & Kebaikan & 2760 & 4000 & 69 & Baik \\
& Hati & & & & \\
3 & Integritas & 3815 & 6000 & 63,5 & Cukup \\
& & & 8 & \\
\hline Kepercayaan & 10607 & $\begin{array}{c}1800 \\
0\end{array}$ & $\begin{array}{c}60,9 \\
9\end{array}$ & $\begin{array}{c}\text { Cukup } \\
\text { Tinggi }\end{array}$
\end{tabular}

Sumber: Data primer diolah (2020) Berdasarkan tabel di atas, diketahui penilaian terhadap variabel kepercayaan terhadap produk di Lazada Indonesia menghasilkan nilai total skor sebesar 10607 dengan persentase sebesar $60,99 \%$ berada pada kategori cukup tinggi. Hal ini didasarkan pada penilaian memiliki kemampuan yang tidak baik, memiliki kebaikan hati yang baik, dan integritas yang cukup. Total skor tertinggi pada indicator kemampuan, dan terendah pada indikator kebaikan hati.

\section{Rekapitulasi Hasil Penilaian Konsumen pada Variabel Persepsi Kemudahan Penggunaan ( $\left.2_{2}\right)$}

\begin{tabular}{|c|c|c|c|c|c|}
\hline \multirow[b]{2}{*}{$\begin{array}{l}\mathbf{N} \\
\mathbf{0}\end{array}$} & \multirow[b]{2}{*}{$\begin{array}{c}\text { Indikato } \\
\mathbf{r}\end{array}$} & \multicolumn{2}{|c|}{ Total Skor } & \multirow[b]{2}{*}{$\%$} & \multirow[b]{2}{*}{$\begin{array}{c}\text { Katego } \\
\text { ri }\end{array}$} \\
\hline & & $\begin{array}{c}\text { Aktu } \\
\text { al }\end{array}$ & Ideal & & \\
\hline 1 & Fleksibel & 4555 & 6000 & $\begin{array}{c}75,9 \\
2\end{array}$ & Baik \\
\hline 2 & $\begin{array}{l}\text { Mudah } \\
\text { dipelajar } \\
\text { i }\end{array}$ & 2940 & 4000 & 73,5 & Baik \\
\hline 3 & $\begin{array}{l}\text { Prosedur } \\
\text { jelas }\end{array}$ & 5948 & 8000 & $\begin{array}{c}74,3 \\
5 \\
\end{array}$ & Baik \\
\hline \multicolumn{2}{|c|}{$\begin{array}{c}\text { Persepsi } \\
\text { Kemudahan } \\
\text { Penggunaan }\end{array}$} & 13443 & $\begin{array}{c}1800 \\
0\end{array}$ & $\begin{array}{c}74,6 \\
8\end{array}$ & Mudah \\
\hline
\end{tabular}
Sumber: Data primer diolah (2020)

Berdasarkan tabel di atas, diketahui penilaian terhadap variabel persepsi kemudahan penggunaan aplikasi Lazada Indonesia menghasilkan nilai total skor aktual sebesar 13443 dengan persentase sebesar $74,68 \%$ berada pada kategori mudah.Hal ini didasarkan pada penilaian bahwa fleksibel yang 
dinilai baik, mudah dipelajari yang dinilai baik, dan memiliki prosedur jelas yang baik. Skor aktual tertinggi pada indicator prosedur jelas dan skor terendah pada indicator mudah dipelajari.

\section{Rekapitulasi Hasil Penilaian Konsumen pada Variabel Persepsi \\ Kenyamanan( $(3)$}

\begin{tabular}{|c|c|c|c|c|c|}
\hline \multirow[b]{2}{*}{$\begin{array}{l}\mathbf{N} \\
\mathbf{0}\end{array}$} & \multirow[b]{2}{*}{ Indikator } & \multicolumn{2}{|c|}{ Total Skor } & \multirow[b]{2}{*}{$\%$} & \multirow{2}{*}{$\begin{array}{c}\text { Katego } \\
\text { ri }\end{array}$} \\
\hline & & $\begin{array}{c}\text { Aktu } \\
\text { al }\end{array}$ & $\begin{array}{c}\text { Idea } \\
\text { I }\end{array}$ & & \\
\hline 1 & $\begin{array}{l}\text { Kenyaman } \\
\text { an } \\
\text { Bertransak } \\
\text { si }\end{array}$ & 2681 & 4000 & $\begin{array}{c}67,0 \\
2\end{array}$ & Cukup \\
\hline 2 & $\begin{array}{l}\text { Desain } \\
\text { yang } \\
\text { menarik }\end{array}$ & 4051 & 6000 & $\begin{array}{c}67,5 \\
2\end{array}$ & Cukup \\
\hline 3 & $\begin{array}{l}\text { Kesenanga } \\
\mathrm{n}\end{array}$ & 4113 & 6000 & $\begin{array}{c}68,5 \\
5 \\
\end{array}$ & Baik \\
\hline & $\begin{array}{l}\text { Persepsi } \\
\text { nyamanan }\end{array}$ & $\begin{array}{c}1084 \\
5\end{array}$ & $\begin{array}{c}1600 \\
0\end{array}$ & $\begin{array}{c}67,7 \\
8\end{array}$ & $\begin{array}{l}\text { Cukup } \\
\text { Nikmat }\end{array}$ \\
\hline
\end{tabular}

Sumber: Data primer diolah (2020)

Berdasarkan tabel di atas, diketahui penilaian terhadap variabel persepsi kenyamanan konsumen Lazada Indonesia menghasilkan nilai total skor sebesar 10845 dengan persentase sebesar $67,78 \%$ berada pada kategori cukup nikmat. Hal ini berdasarkan pada hasil penilaian terhadap masing-masing indikator, yaitu kenyamanan bertransaksi dinilai cukup, desain yang menarik dinilai cukup, dan kesenangan dinilai baik. Skor tertinggi pada indicator kesenangan, sementara skor terendah pada indicator kenyamanan bertransaksi.

\begin{tabular}{|c|c|c|c|c|c|}
\hline & & al & 1 & & \\
\hline \multirow[t]{2}{*}{1} & Frekuensi & 1986 & 4000 & 49,6 & Tidak \\
\hline & Pembelian & & & 5 & Baik \\
\hline \multirow[t]{2}{*}{2} & Komitmen & 3062 & 6000 & 51,0 & Tidak \\
\hline & Pelanggan & & & 3 & Baik \\
\hline 3 & $\begin{array}{l}\text { Rekomend } \\
\text { asi Positif }\end{array}$ & 2216 & 4000 & 55,4 & Cukup \\
\hline & $\begin{array}{l}\text { Intensi } \\
\text { embelian } \\
\text { Ulang }\end{array}$ & 7264 & $\begin{array}{c}1400 \\
0\end{array}$ & $\begin{array}{c}51,8 \\
9\end{array}$ & Rendah \\
\hline
\end{tabular}

Sumber: Data primer diolah (2020)

Berdasarkan tabel di atas, diketahui penilaian terhadap persepsi konsumen Lazada Indonesia terhadap variabel intensi pembelian ulang pada Lazada Indonesia menghasilkan nilai total skorsebesar 7264 dengan persentase sebesar $51,89 \%$ berada pada kategori rendah. Hal ini berdasarkan pada penilaian terhadap indikator variabel, yaitu indikator frekuensi pembelian memiliki skor 1986 (49,65\%) kategori rendah, indikator komitmen pelanggan memiliki skor 3062 $(51,03 \%)$ berada pada kategori rendah dan indikator rekomendasi positif memiliki skor $2216(55,4 \%)$ berada pada kategori cukup tinggi.

\section{III.2. Verification Analysis}

Berdasarkan hasil penelitian dapat dikatakan bahwa model dikatakan fit dengan output sebagai berikut.

\section{Hasil Goodness of Fit Index}

\begin{tabular}{|c|c|c|c|}
\hline $\begin{array}{l}\mathbf{N} \\
\mathbf{0}\end{array}$ & $\begin{array}{l}\text { Ukuran Uji } \\
\text { Kecocokkan } \\
\text { Model }\end{array}$ & Nilai Kritis & $\begin{array}{c}\text { Kecocokan } \\
\text { Model }\end{array}$ \\
\hline 1 & $\begin{array}{c}\chi^{2}-\text { Chi-square }= \\
294,32\end{array}$ & $\begin{array}{l}<\chi^{2}-\text { Chi- } \\
\text { square tabel }\end{array}$ & fit \\
\hline 2 & $\begin{array}{c}\text { Probabilitas dari } \\
\chi_{\text {hitung }}^{2}=0,60\end{array}$ & $\begin{array}{l}\geq 0,05 \\
\geq 0,05\end{array}$ & fit \\
\hline 3 & RMSEA $=0,01$ & $\begin{array}{l}\leq 0,08 \\
\leq 0,08\end{array}$ & fit \\
\hline 4 & $\mathrm{NFI}=0,97$ & $\geq 0,9 \geq 0,9$ & fit \\
\hline$\overline{e g 05}$ & $\mathrm{NNFI}=0,97$ & $\geq 0,9 \geq 0,9$ & fit \\
\hline 6 & $\mathrm{CFI}=0,98$ & $\geq 0,9$ & fit \\
\hline
\end{tabular}




\begin{tabular}{cccl}
\hline $\mathbf{7}$ & IFI $=0,98$ & $\geq 0,9 \geq 0,9$ & fit \\
\hline $\mathbf{8}$ & RFI $=0,96$ & $\geq 0,9 \geq 0,9$ & fit \\
\hline $\mathbf{9}$ & RMR $=0,02$ & $\leq 0,05$ & fit \\
& & $\leq 0,05$ & \\
\hline $\mathbf{1 0}$ & SRMR $=0,04$ & $\leq 0,05$ & fit \\
& & $\leq 0,05$ & fit \\
\hline $\mathbf{1 1}$ & GFI $=0,98$ & $\geq 0,09$ & fit \\
\hline $\mathbf{1 2}$ & AGFI $=0,82$ & $\begin{array}{c}0,8 \leq \mathrm{AGFI}< \\
\\
\end{array}$ & 0,9 \\
& & $0,8 \leq$ AGFI $<($ \\
\end{tabular}

Hasil penelitian mengenai kepercayaan, persepsi kemudahan penggunaan, persepsi kenyamanan dan intensi pembelian ulang pada konsumen Lazada Indonesia dapat dilihat pada gambar berikut.

Sumber: Output Lisrel (2020)

Ringkasan Matrik Korelasi

(Correlation Matrix)

\begin{tabular}{cccccc}
\hline $\mathbf{N}$ & Keteranga & \multicolumn{4}{c}{ Korelasi } \\
\cline { 3 - 6 } $\mathbf{0}$ & $\mathbf{n}$ & $\xi 1$ & $\xi 2$ & $\xi 3$ & $\eta$ \\
\hline 1 & $\mathrm{X} 1$ & 1.00 & & & \\
& & 0 & & & \\
2 & $\mathrm{X} 2$ & 0.78 & 1.00 & & \\
& & 6 & 0 & & \\
3 & $\mathrm{X} 3$ & 0.80 & 0.87 & 1.00 & \\
& & 7 & 6 & 0 & \\
4 & $\mathrm{Y}$ & 0.54 & 0.44 & 0.59 & 1.00 \\
& & 5 & 9 & 9 & 0 \\
\hline
\end{tabular}

Keterangan: $\boldsymbol{\xi} \mathbf{1}=$ Kepercayaan;

$\xi_{2}=$ Persepsi Kemudahan Penggunaan;

$\boldsymbol{\xi} 3=$ Persepsi Kenyamanan; $\mathbf{\eta}=$ Intensi

Pembelian Ulang

Sumber: Output Lisrel, 2020

Berdasarkan tabel di atas mengenai ringkasan correlation matrix pada Lisrel, diperoleh data mengenai korelasi antar variabel penelitian. Nilai korelasi variabel kepercayaan terhadap variabel intensi pembelian ulang sebesar 0,545 yaitu memiliki korelasi sedang. Nilai korelasi variabel persepsi kemudahan penggunaan dan persepsi kenyamanan terhadap variabel intensi pembelian ulang masingmasing sebesar 0,449 dan 0,599 yaitu memiliki korelasi sedang. Oleh karenanya dapat disimpulakan bahwa kepercayaan, persepsi kemudahan penggunaan dan persepsi kenyamanan konsumen Lazada Indonesia memiliki korelasi sedang terhadap intensi pembelian ulang.

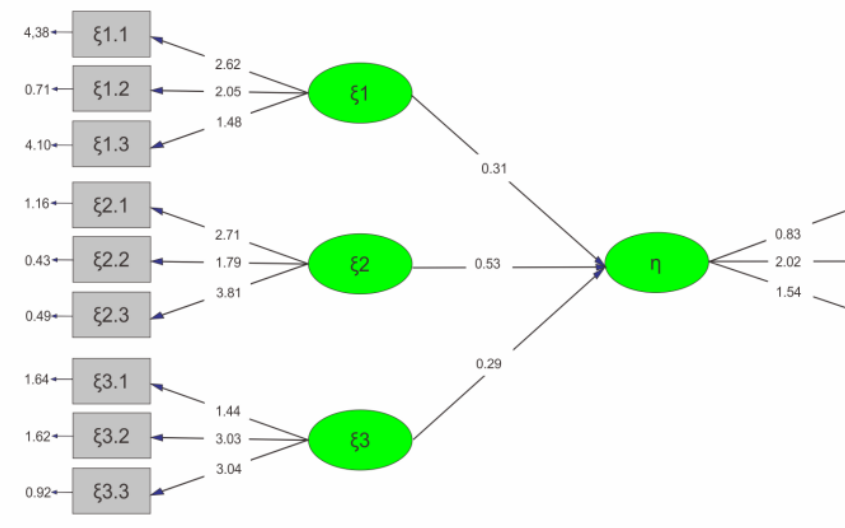

Sumber : Output Lisrel, 2020

Keterangan: $\boldsymbol{\xi} \mathbf{1}=$ Kepercayaan;

$\xi_{2}=$ Persepsi Kemudahan Penggunaan;

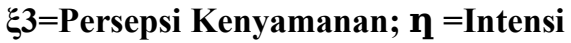

Pembelian Ulang

Gambar 4.2

Hasil Analisis Jalur (Estimates)

Pengaruh Kepercayaan, Persepsi

Kemudahan Penggunaan, dan Persepsi

KenyamananterhadapIntensiPemb elian Ulang

Berdasarkan hasil analisis
dengan menggunakan $\begin{array}{r}\text { SEM, } \\ \text { diperoleh persamaan struktural } \\ \text { sebagai berikut. }\end{array}$

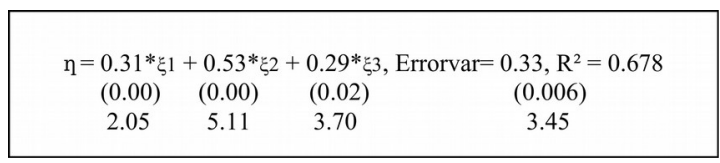

Keterangan: $\xi 1=$ Kepercayaan; $\xi 2=$ Persepsi Kemudahan Penggunaan; $\xi 3=$ =ersepsi Kenyamanan; $\eta$ =IntensiPembelian Ulang Sumber: Output Lisrel, 2020

Gambar 4.3 Persamaan Struktural 
Dari persamaan substruktur di atas, diketahui nilai koefisien jalur variable kepercayaan $(\xi 1)$ terhadap intensi pembelian ulang (n) yaitu sebesar 0,31. Artinya dalam keadaan konstan (persepsi kemudahan penggunaan ( $(2)$ dan persepsi kenyamanan $(\xi 3)=0)$, kepercayaan mempengaruhi intensi pembelian ulang sebesar 0,31. Koefisien jalurpersepsi kemudahan penggunaan ( $\xi 2)$ terhadap intensi pembelian ulang sebesar 0,53 . Artinya dalam keadaan

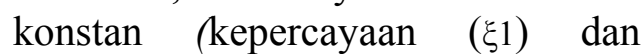
persepsi kenyamanan ( $\xi 3)=0$ ), persepsikemudahan penggunaan mempengaruhi intensi pembelian ulang sebesar 0,53. Sedangkan koefisien jalur persepsi kenyamanan

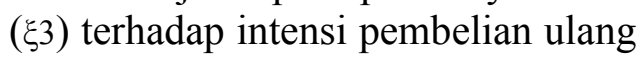
sebesar 0,29. Artinya dalam keadaan konstan (kepercayaan ( $\xi 1)$ dan persepsi kemudahan penggunaan ( $(\xi 2)$ $=0$ ), persepsi kenyamanan mempengaruhi intensi pembelian ulang sebesar 0,29. Dengan nilai errorvar sebesar 0,33 dan nilai $\mathrm{R}^{2}$ sebesar 0,67. Hasil nilai $R$ Square menandakan besaran pengaruh terhadap intensi pembelian ulang di Lazada Indonesia yaitu dipengaruhi oleh kepercayaan, persepsi kemudahan penggunaan dan persepsi kenyamanan lebih dari 50\%.

Selanjutnya, untuk mengetahui besarnya pengaruh variabel kepercayaan, kemudahan penggunaan dan persepsi kenyamanan terhadap intensi pembelian ulang di Lazada Indonesia dapat dilihat dari tabel berikut.

Tabel 4.30

Pengaruh Langsung (Direct Effect) dan Pengaruh Tidak Langsung (Indirect Effect) Kepercayaan,

\section{Persepsi Kemudahan Penggunaan dan Persepsi Kenyamanan terhadap Intensi Pembelian Ulang di Lazada Indonesia}

\begin{tabular}{|c|c|c|c|}
\hline $\begin{array}{l}\text { Keterang } \\
\text { an } \\
\text { Pengaru } \\
\text { h Antar } \\
\text { Variabel }\end{array}$ & $\begin{array}{c}\text { Pengar } \\
\text { uh } \\
\text { Langsu } \\
\text { ng } \\
\text { (Direct } \\
\text { Effect) }\end{array}$ & $\begin{array}{c}\text { Pengaruh } \\
\text { Tidak } \\
\text { Langsung } \\
\text { (Indirect } \\
\text { Effect) }\end{array}$ & $\begin{array}{c}\text { Pengar } \\
\text { uh } \\
\text { Total } \\
\text { (Total } \\
\text { Effect) }\end{array}$ \\
\hline$\xi 1_{\text {口 }} \eta$ & $(0,31)^{2}$ & - & 0,096 \\
\hline $\begin{array}{l}\xi 1 \text { ロ } \xi^{2} \text { ロ } \\
\eta\end{array}$ & - & $\begin{array}{c}(0,31)(0,23) \\
(0,53)\end{array}$ & 0,038 \\
\hline $\begin{array}{l}\xi 1 \text { ロ } 3^{3} \text { 口 } \\
\eta\end{array}$ & & $\begin{array}{c}(0,31)(0,22) \\
(0,29)\end{array}$ & 0,020 \\
\hline \multicolumn{3}{|c|}{$\begin{array}{l}\text { Total pengaruh kepercayaan } \\
\text { terhadap intensi pembelian ulang di } \\
\text { Lazada Indonesia }\end{array}$} & 0,154 \\
\hline$\xi 2$ 口 & $(0,53)^{2}$ & - & 0,281 \\
\hline $\begin{array}{l}\xi 2 \text { ロ } \xi 1 \text { ロ } \\
\eta\end{array}$ & - & $\begin{array}{c}(0,53)(0,23) \\
(0,31)\end{array}$ & 0,038 \\
\hline $\begin{array}{l}\xi 2 \text { 口 } \\
\xi 3_{\text {口 }} \mathrm{n}\end{array}$ & - & $\begin{array}{c}(0,53)(0,33) \\
(0,29)\end{array}$ & 0,051 \\
\hline \multicolumn{3}{|c|}{$\begin{array}{l}\text { Total pengaruh persepsi kemudahan } \\
\text { penggunaan terhadap intensi } \\
\text { pembelian ulang di Lazada Indonesia }\end{array}$} & 0,369 \\
\hline$\xi 3$ 口Y & $(0,29)^{2}$ & - & 0,084 \\
\hline $\begin{array}{l}\xi 3 \text { ロ } \xi 1 \text { ロ } \\
\eta\end{array}$ & - & $\begin{array}{c}(0,29) \times(0,22) \times( \\
0,31)\end{array}$ & 0,020 \\
\hline $\begin{array}{l}\xi 3 \text { ロ } \xi_{2} \text { ロ } \\
\eta\end{array}$ & - & $\begin{array}{c}(0,29) \times(0,33) \times( \\
0,53)\end{array}$ & 0,051 \\
\hline \multicolumn{3}{|c|}{$\begin{array}{l}\text { Total pengaruh persepsi kenyamanan } \\
\text { terhadap intensi pembelian ulang di } \\
\text { Lazada Indonesia }\end{array}$} & 0,155 \\
\hline \multicolumn{3}{|c|}{ Pengaruh Total/R-Square $\left(R^{2}\right)$} & 0,678 \\
\hline \multicolumn{3}{|c|}{ Koefisien Determinasi $\left(\mathrm{R}^{2}\right.$ x $\left.100 \%\right)$} & $67,8 \%$ \\
\hline \multicolumn{3}{|c|}{$\begin{array}{l}\text { Koefisien Non-determinasi }\left(1-\mathrm{R}^{2} \mathrm{x}\right. \\
100 \%)\end{array}$} & $32,2 \%$ \\
\hline
\end{tabular}

Sumber: Output Lisrel diolah, 2020

Keterangan: $\xi 1=$ Kepercayaan; $\xi 2=$ Persepsi Kemudahan penggunaan; $\xi 3=$ Persepsi kenyamanan; $\eta=$ Intensi pembelian ulang

Berdasarkan Tabel di atas, dapat diketahui bahwa pengaruh langsung variabel kepercayaan terhadap intensi pembelian ulang adalah 0,096, artinya kepercayaan konsumen terhadap intensi pembelian ulang di Lazada Indonesia 


\begin{tabular}{|c|c|c|c|c|c}
\hline Variabel & $\begin{array}{c}\text { Koefisien } \\
\text { Jalur }\end{array}$ & thitung & $\begin{array}{c}\text { ttabel } \\
(\mathbf{0}=\mathbf{5} \%)\end{array}$ & $\begin{array}{c}\text { Nilai } \\
\text { Signifikansi }\end{array}$ & Keterangan \\
\hline Kepercayaan & 0,31 & 2,05 & 1,65 & 0,00 & $\begin{array}{c}\text { Berpengaruh } \\
\text { Signifikan }\end{array}$ \\
\hline $\begin{array}{c}\text { Persepsi } \\
\text { Kemudahan } \\
\text { Penggunaan }\end{array}$ & 0,53 & 5,11 & 1,65 & 0,00 & $\begin{array}{c}\text { Berpengaruh } \\
\text { Signifikan }\end{array}$ \\
\hline $\begin{array}{c}\text { Persepsi } \\
\text { Kenyamanan }\end{array}$ & 0,29 & 3,70 & 1,65 & 0,02 & $\begin{array}{c}\text { Berpengaruh } \\
\text { Signifikan }\end{array}$ \\
\hline $\begin{array}{l}\mathrm{R}^{2}=0,678 \\
\text { Fhitung }=200,49 \\
\text { Ftabel }=2,60\end{array}$ & & & \\
\hline
\end{tabular}

\section{Sumber: Output Lisrel, 2020}

Hasil analisis menghasilkan nilai koefisien jalur variabel kepercayaan sebesar 0,31. Nilai signifikansi variabel kepercayaan sebesar0,00 lebih kecil dari 0,05 $(\alpha=$ $5 \%$ ) dimana nilai $t_{\text {hitung }}$ sebesar 2,05 lebih besar daripada $t_{\text {tabel }}=1,65(\alpha$ $=5 \%$ ). Dengan demikian hipotesis penelitian terbukti bahwa kepercayaan berpengaruh secara signifikan terhadap intensi pembelian ulang pada Lazada Indonesia.

Nilai koefisien variabel persepsi kemudahan penggunaan sebesar 0,53.Nilai signifikansi variable persepsi kemudahan penggunaan sebesar 0,00 lebih kecil dari $0,05(\alpha=5 \%)$ dimana nilai $t_{\text {hitung }}$ sebesar 3,70 lebih besar daripada $t_{\text {tabel }}$ $=1,65 \quad(\alpha=5 \%)$. Dengan demikian hipotesis penelitian terbukti bahwa persepsi kemudahan penggunaan berpengaruh secara signifikan terhadap intensi pembelian ulang pada Lazada Indonesia.

Nilai koefisien variabel persepsi kenyamanan sebesar 0,29.Nilai signifikansi variabel kemudahan penggunaan sebesar0,02 lebih kecil dari 0,05 $(\alpha=5 \%)$ dimana nilai $t_{\text {hitung }}$ sebesar 3,70 lebih besar daripada $t_{\text {tabel }}=1,65 \quad(\alpha=5 \%)$. Dengan demikian hipotesis penelitian terbukti bahwa persepsi kenyamanan berpengaruh secara signifikan terhadap intensi pembelian ulang pada Lazada Indonesia.

Sedangkan pengaruh variabel kepercayaan, persepsi kemudahan penggunaan, dan persepsi kenyamanan terhadap intensi pembelian ulang dapat dilihat dari nilai R-Square $\left(\mathrm{R}^{2}\right)$, yaitu sebesar 0,678 . Untuk menguji pengaruh simultan pengaruh variabel kepercayaan, persepsi kemudahan penggunaan, persepsi kenyamanan terhadap intensi pembelian ulang pada Lazada Indonesia dapat dihitung dengan formulasi berikut ini:

$$
\begin{gathered}
F_{\text {hitung }}=\frac{(n-k-1) R^{2}}{k\left(1-R^{2}\right)} \\
\mathrm{F}_{\text {hitung }}=\frac{(400-4-1) 0,67}{4(1-0,67)} \\
\mathrm{F}_{\text {hitung }}=\frac{264,65}{1,32}=200,49
\end{gathered}
$$

Berdasarkan hasil perhitungan di atas, diketahui nilai $\mathrm{F}$ hitung adalah sebesar 176,34 lebih besar dari $\mathrm{F}_{\text {tabel }}=2,60(\mathrm{DF} 1=\mathrm{k}-1$; DF2 = n-k-1). Dengan demikian hipotesis secara simultan variabel kepercayaan, persepsi kemudahan penggunaan dan persepsi kenyamanan berpengaruh terhadap intensi pembelian ulang di Lazada Indonesia.

\section{CONCLUSION}

Kepercayaan konsumen pada Lazada Indonesia memiliki kategori cukup tinggi. Persepsi kemudahan penggunaan konsumen dalam 
menggunakan platform Lazada Indonesia memiliki kategori mudah. Persepsi kenyamanan konsumen berbelanja pada Lazada Indonesia memiliki kategori cukup nikmat. Intensi pembelian ulang konsumen pada Lazada Indonesia memiliki kategori rendah. Kepercayaan konsumen, persepsi kemudahan penggunaan dan persepsi kenyamanan konsumen Lazada Indonesia berpengaruh terhadap intensi pembelian ulang baik secara parsial maupun simultan. Kepercayaan konsumen, persepsi kemudahan penggunaan dan persepsi kenyamanan konsumen dalam berbelanja di Lazada Indonesia dapat menciptakan pengalaman yang berkesan, sehingga besar kemungkinan konsumen melakukan pembelian ulang di Lazada akan tinggi.

\section{ACKNOWLEDGEMENT}

Penulis ingin mengucapkan terima kasih kepada Lazada Indonesia dan seluruh konsumen yang ikut berpartisipasi dalam penulisan ini, juga kepada semua pihak yang telah membantu sehingga paper ini dapat diselesaikan.

\section{REFFERENCES}

Baskara, I. M. A., \& Sukaatmadja, I. P. G. (2016). Pengaruh Online Trust Dan Perceived Enjoyment Terhadap Online Shopping Satisfaction Dan Repurchase Intention Lazada Indonesia. E-Jurnal Manajemen, 5(11).
Hasibuan, Afif Hazly. 2019. "Hubungan Intensitas Penggunaan Internet, Intensitas Komunikasi Peer Group, Status Sosial Ekonomi dengan Intensitas Membaca Buku Pada Remaja Kota Semarang”. Jurnal Online Melalui :https://ejournal3.undip.ac.id

Mahkota, Andi Putra. Suyadi, Imam. Riyadi. 2014. "Pengaruh Kepercayaan dan Kenyamanan Terhadap Keputusan Pembelian Online". Jurnal Administrasi Bisnis Vol. 8 No. 2. Jurnal Online Melalui http://administrasibisnis. studentjournal.ub.ac.id/index. php/jab/article/viewFile/359/5 54

Oktarini, M. A. S., \& Wardana, I. M. (2018). Pengaruh Perceived Ease of Use dan Perceived Enjoyment terhadap

Customer Satisfaction dan Repurchase

Intention. INOBIS: Jurnal Inovasi Bisnis dan Manajemen Indonesia, 1(2), 227-237.

Puspitasari, I., \& Briliana, v. (2017). Pengaruh Perceived Ease-ofUse, Perceived Usefulness, Trust dan Perceived Enjoyment terhadap Repurchase Intention (studi kasus pada Website Zalora Indonesia). Jurnal Bisnis dan Akuntansi, 19(2), 171-182.

Putra, D. A., \& Verinita, V. (2018). ANALISIS FAKTORFAKTOR YANG MEMPENGARUHI REPURCHASE 
INTENTION KONSUMEN

PADA SITUS JUAL BELI

ONLINE LAZADA. CO.

ID. JURNAL STIE

SEMARANG, 10(3), 49-55.

Putra, I. P. A. P. A., Sukaatmadja, I. P. G., \& Giantari, I. G. K. (2016). Pengaruh Persepsi Kemudahan Penggunaan, Persepsi Risiko, Terhadap Kepercayaan dan Niat Beli Eticket pada Situs Traveloka. E-Jurnal Ekonomi Dan Bisnis Universitas Udayana.

Saragih, S. R., \& Aksari, N. M. A. (2019). Peran Kepercayaan Dalam Memediasi Persepsi Nilai Terhadap Niat Beli Ulang Green Coffee Di Kota Denpasar. E-Jurnal

Manajemen, 8(3), 1457-1486.

Sianadewi, J. H., Widyarini, L. A., \& Wibowo, W. (2018). Pengaruh Perceived Social Presence, Perceived Ease Of Use, Perceived Usefulness, Dan Attitude Towards Online Shopping Terhadap Niat Beli Pada Jakarta Notebook. Com. Kajian Ilmiah Mahasiswa Manajemen, 6(2), 104-115.

Wahdiniwaty, Rahma, Deden A. Wahab Sya'roni, and Eko Budi Setiawan. "MODEL POTENSI INDUSTRI KREATIF SKALA USAHA MIKRO KECIL DAN MENENGAH BERBASIS SISTEM INFORMASI GEOGRAFIS DI KABUPATEN BANDUNG BARAT DALAM UPAYA MENINGKATKAN
PENDAPATAN." Jurnal

Manajemen Pemasaran 13.2 (2019): 54-60.

Wahdiniwaty, Rahma, Eko Budi Setiawan, and Deden A. Wahab. "Implementation of Recommendation Model for Determining the Marketing Area Location of Creative Industry Products." International Conference on Business, Economic, Social Science and Humanities (ICOBEST 2018). Atlantis Press, 2018.

Wahdiniwaty, Rahma, et al. "Application Model for Travel Recommendations Based on Android." IJNMT (International Journal of New Media Technology) 6.1 (2019): 9-16.

Wahdiniwaty, Rahma, Eko Budi Setiawan, and Deden A. Wahab. "Comparative Analysis of Software Quality Model In The Selection of Marketplace E-Commerce." 2018 International Conference on Information Technology Systems and Innovation (ICITSI). IEEE, 2018.

Wong, David. 2017. "Pengaruh Ability, Benevolence, dan Integrity Terhadap Trust, Serta Implikasinya Terhadap Partisipasi Pelanggan ECommerce". Jurnal Riset Manajemen dan Bisnis (JRMB) fakultas Ekonomi UNIAT Vol. 2 No.2, Juni 
2017:155-168. ISSN : 2527-

7502

Yonaldi, S., \& Defita, F. M. (2019).

Analisis Pengaruh Trust, Perceived of Use, dan Perceived Risk terhadap Minat Beli Online Shop Menggunakan Instagram di Kota Padang. Manajemen dan Kewirausahaan, 10(2), 16-23.

Yunita, M., \& Ilhami, M. D. 2019. "Pengaruh Trust terhadap Komitmen Pelanggan dalam Membeli suatu Produk (studi kasus Surya Bakery Kebun Tebeng Kota Bengkulu). Jurnal Ilmiah Akuntansi, Manajemen \& Ekonomi Islam Vol.18. No.1 ISSN:1412-2022 